\title{
Rural History: the prospect before us, revisited
}

\author{
Carl Griffin ${ }^{1 \star}$ and Tom Williamson ${ }^{2}$ \\ ${ }^{1}$ Department of Geography, University of Sussex, Brighton, United Kingdom and ${ }^{2}$ School of History, University of East \\ Anglia, Norwich, United Kingdom \\ *Corresponding author. Email: C.J.Griffin@sussex.ac.uk
}

Setting out their vision in the first issue of Rural History published in April 1990, editors Liz Bellamy, Keith Snell and Tom Williamson emphasised that rural history had often been seen as synonymous with a narrowly economistic agricultural history, and that exciting and innovative work deploying other methodological perspectives had been left 'scattered across a range of disciplines and subdisciplines'. Sixty-three issues later, and with only one of the original editors still in place, not only are we confident that Rural History has established itself as the home for such work, but also that it has played a central role in transforming the study of our subject along a more nuanced and eclectic line. Of course, a journal is only as good, and as influential, as the papers it publishes, and key roles in eliciting and attracting the most innovative research have been played by Liz Bellamy, who retired to pursue other projects in 2014, and, in particular, by Professor Keith Snell, who steps down as one of the editors in this issue. Thirty-one years is an extraordinarily long time to act as a journal editor, not least given the current pressures on academics to publish and attract grant income, rather than promote their discipline or serve the wider scholarly community. Keith has been a model editor: efficient and prompt; patient with his fellow editors when others might have been quick to berate; generous in his feedback to those who submitted work to the journal; and a wonderful supporter of doctoral students and early career researchers whose work we are especially proud to publish. It is therefore particularly appropriate that this issue contains a paper by Keith himself on the rural writings of Ronald Blythe. It exemplifies his work, and his approach to rural history: erudite and witty; widely read and deeply humane; acutely attuned to local dynamics and yet always subtly speaking to broader phenomena and generalisable patterns. He is a historian of the countryside, yet wary of false geographical (and intellectual) divisions. In tribute to his years of service, Cambridge University Press have made freely available sample chapters of his several Cambridge-published books, his several papers published in Cambridge, and a selection of papers from this journal that Keith has expertly curated, papers that speak to Keith's time on the journal and his intellectual passions.

But the end of one era in the history of the journal is unquestionably the opening of another, and we also take this opportunity to welcome Professor Annie Tindley to the editorial team. Annie is a scholar with a formidable reputation in the study of the history and heritage of land, widely known for her work on landownership, the politics of land reform, and land management in Scotland and Ireland, as well as in a wider British and imperial context. We are also in the process of refreshing our wider editorial board, saying farewell to some old friends and supporters, while welcoming members of a new generation of researchers.

So, in the spirit of the initial editorial, what is before us? We remain true to the founding principles of the journal and, in particular, to our commitment to publishing the very best in interdisciplinary research on our rural pasts. Over the past thirty-one years we have broken new ground, with innovative articles on rural environmental history, rural custom and heritage, representations of the rural, rural poverty and policy, landscape history, material cultures, gender 
and sexuality, rural protest and resistance. We have blazed a trail in reimagining the role and place of animals, plants and technologies, in writing a conceptually rich history of the farm, fields, and forests, beyond the ledger and the account book. But by way of continuing to influence the wider field and informing future directions we are also making some changes to the nature of material we publish. We have made an editorial policy to no longer commission book reviews, feeling that other journals are better placed than us to undertake this role. We will dedicate the page space thus liberated to two new initiatives. Firstly, we will commission extended review essays on the themes of 'Classics in Rural History Revisited', which will critically examine the influence and legacy of seminal texts of rural history; and secondly, we will invite key scholars to share their views on 'Where Next in Rural History?', a mix of historiographical reviews of aspects of rural history combined with agenda-setting calls to research. Subsequent issues from the next volume will comprise, alternately, one such essay.

Increasingly, we receive a large volume of submissions from beyond the Anglophone world. If Rural History has always been alert to globalities - the first two volumes containing papers on Greece, Italy, Romania, and Russia - we are now more than ever conscious of a seemingly paradoxical need to both be true to the spirit of writing more-than-idiographic histories of places and communities and yet at the same time to be alert to the always more-than-local contexts in which all history is made, and in which all rural history is read. To that end, we welcome submissions from all scholars of the rural past, whatever their discipline and geographical focus, providing they stay true to our principles of publishing rigorous, ground-breaking work that ignores established disciplinary boundaries and which speaks in new ways to the history of the rural. If the English-speaking world and Europe remains by dint of submissions our core geographical focus, we are delighted to publish work that speaks to all cultures and all rural pasts.

Cite this article: Griffin, C. and Williamson, T (2021). Rural History: the prospect before us, revisited. Rural History 32, 1-2. https://doi.org/10.1017/S0956793321000042 